\title{
Flexible soils amplified the damage in the 2010 Haiti earthquake
}

\author{
R. O. de León \\ Sciences Academy of Dominican Republic
}

\begin{abstract}
On January $12^{\text {th }}, 2010$, a 7.0 magnitude earthquake with an epicenter $15 \mathrm{~km} \mathrm{SW}$ of the city of Port-au-Prince and a hypocenter at $10 \mathrm{~km}$ depth, caused 316,000 deaths, 350,000 injured people, and destroyed 300,000 homes that left 1,500,000 homeless. This is the worst global seismic tragedy of the past 50 years.

All the collapsed buildings in Haiti were raised on soft and flexible clayey soils of bad seismic response, which were deposited on ancient marine channel. In comparison, the buildings raised on Tertiary limestone of the southern slope of the city suffered no damage. This includes the precariously built structures near the epicenter, which lacked any engineering design from the impoverished people who live on the rocky slopes.

Buildings with apparently robust structures, and designed with engineering standards, such as the national palace, the cathedral and the Montana hotel, collapsed when the soft and flexible soils amplified the vibration and the seismic energy of the earthquake. This resulted in greater forces that produced wide lateral displacements at the higher levels of homes and buildings. These forces caused major shear deformations that exceeded the elastic limit of the concrete, leading to failure and the loss of many lives.

Few architectural designs took seismic response into consideration when engineering building projects. The low shear-strength (which may be related to low shear velocity) foundations of many locations were given no differential treatment, in comparison to locally more rigid rock foundations. These engineering deficiencies lead to more seismic disasters around the world.
\end{abstract}

\section{Introduction}

On Tuesday, January $12^{\text {th }}, 2010$ at 4:53 P.M., Haitian time (21:53 UTC), an earthquake of magnitude 7.0, an epicenter approximately 15 kilometers 
southwest of the center of Port-au-Prince, and a hypocenter depth of 10 kilometers, shook the city of Port-au-Prince. The capital of the Republic of Haiti, Port-au-Prince is located on the west side of the Hispaniola island. The earthquake destroyed much of the southern and southwestern areas of the Haitian island, including cities of Léogâne and Jacmel, causing nearly 316,000 deaths, approximately 350,000 wounded, the destruction of 300,000 homes, the collapse of 5,000 school buildings, and left more than 1,500,000 people homeless. The 2010 Haiti earthquake is the largest magnitude earthquake to affect the Haitian Republic since 1770, and is the world's deadliest earthquake of the last 50 years (De León [1]).

Starting on the day after the earthquake, it became apparent that the collapsed buildings in Port-au-Prince, correlated to areas with soft and flexible clay soil foundations, of relative low shear strength. These soils consist of ancient marine channel deposits of the Enriquillo graben valley. The most extensive damage were located in the plains south and west of the city, near the epicenter (figure 1). The granular alluvial fans of the south, and the soft clay soils of the northern plain of Léogâne city, located to the west of Port-au-Prince, saw the greatest structural damage. Ninety percent of the buildings placed on the soft clay of the coastal plain collapsed, including the school at Léogâne, where all the structural columns failed due to strong ground motion (De León [2]).

It is not common for an earthquake of magnitude 7.0 to be capable of producing such total destruction of property and lives, except when low shearstrength soils produce an amplified seismic response, and when buildings erected on those soils do not meet proper criteria of earthquake resistance.

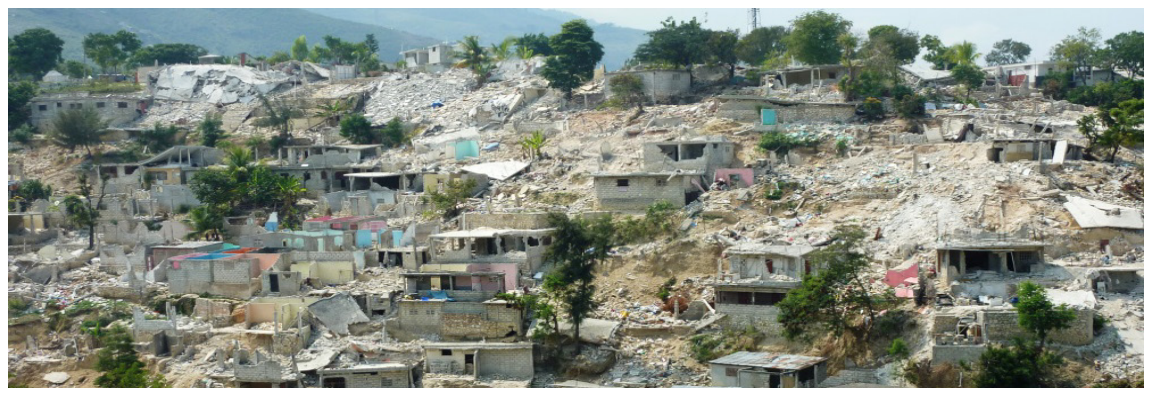

Figure 1: $\quad$ Small village destroyed in the south area of Port au Prince.

A similar situation happened in Mexico City, in September 1985, when amplified shear seismic waves, arriving from an epicenter $320 \mathrm{~km}$ away, caused buildings to collapse over the soft and flexible soils of the ancient Texcoco lake, while buildings over hard rock remained intact.

Propagation velocities of seismic shear waves (Vs) were analyzed using the multichannel analysis of surface waves approach (Park et al. [3], Xia et al. [4]) across the east side of the Port-au-Prince harbor (Figures 2, 3 and 4). The profile image shows a horizon from around $2.0 \mathrm{~m}$ to $4.5 \mathrm{~m}$ deep is a soft and flexible soil horizon, with a Vs of approximately 75 meters per second. Relating this to shear strength, we would expect an amplification of the effects of an earthquake. 


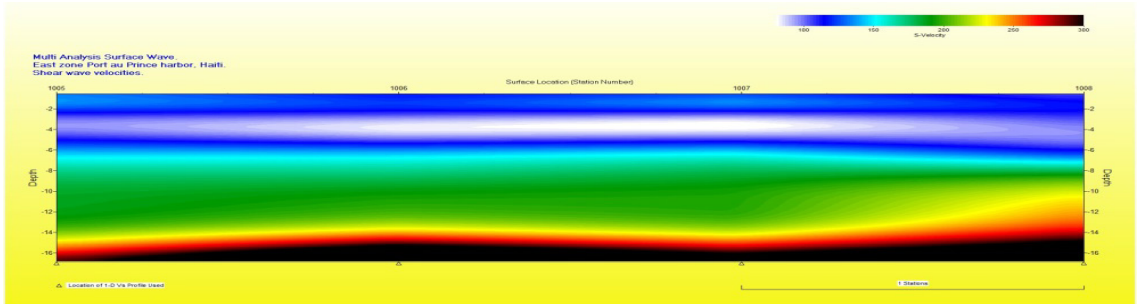

Figure 2: Vs profile showing soft and flexible soils between 2.0 and $4.5 \mathrm{~m}$ deep.

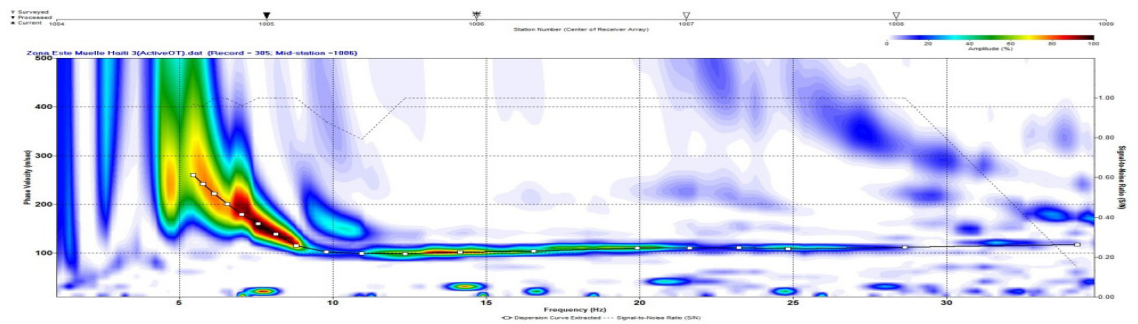

Figure 3: Phase velocity versus frequency plot collectted on the east side of the Port-au-Prince harbor, Haiti.

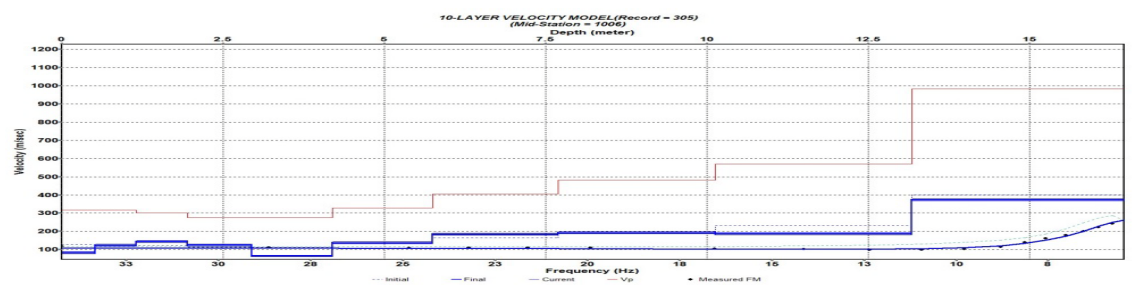

Figure 4: A representative 1D shear-wave velocity profile from the eastern section of our survey.

Exploring the southern mountainous area of Petionville, we found an area where buildings did not suffer any damage. These buildings were erected without any engineering criteria over an exposure of hard limestone bedrock. The citizens use a mixture of limestone cobbles and poor-quality mortar to form a foundation. Over this base, they raised block walls using similar weak mortar, without rebar reinforcement rods, and with few structural columns. Given the widespread destruction, we would expect these poorly built structures to collapse; but they did not, as we can see in figure 5. This is due to the underlying bedrock that has a relatively high shear velocity (and corresponding high shear strength) that avoided amplification of the seismic energy and reduced the shear forces transmitted to the structures (De León [5]). 


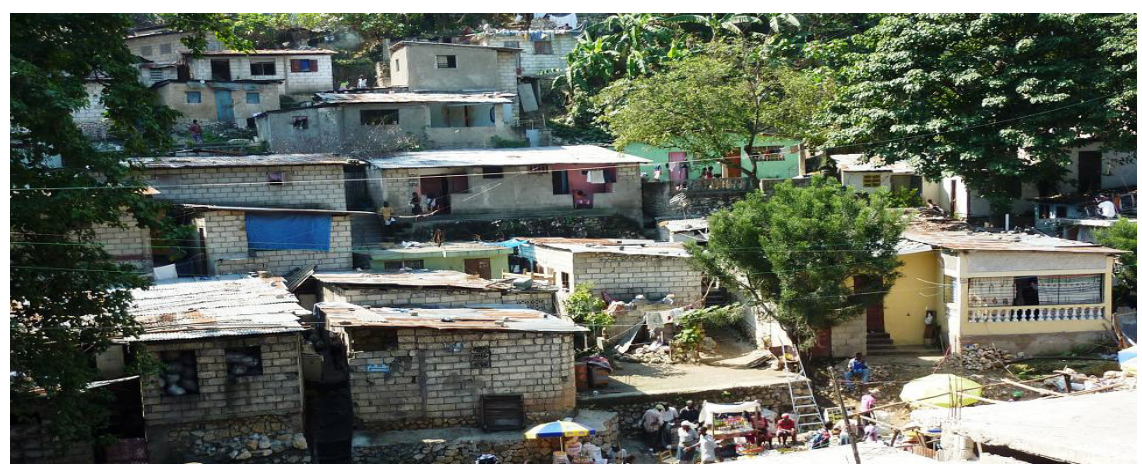

Figure 5: Small village without damage, over hard limestone bedrock.

\section{Major damage from the 2010 Haiti earthquake}

The inspection of areas with and without collapsed buildings relates structural integrity to foundation material, rather than the presence of engineering forethought, or lack thereof. Buildings constructed on the softer material soils were destroyed regardless of engineering improvements. On the other hand, those areas with surface exposures of limestone bedrock had little or no damage even in the presence of ridiculously poor building standards. These low-damage areas were also within walking distance from the epicenter, yet suffered no damage, not even foundation cracks (De León [6]).

The road to Léogâne, and its masonry peripheral walls, broke clear in the sections raised over soft and flexible clay soils, while the roads built over the hard limestone rock, going from Pétionville to Kenscoff and climbing the south mountains, suffered little damage. The road near Fermate, where a 3,500 meters road section lies along the regional tectonic fault responsible for the earthquake and only $14 \mathrm{~km}$ east of the epicenter, sustained no damage.

The Haitian government's palace, raised on the clay soils of the western plain of Port-au-Prince, and next to the point defined by the coordinates $0780935 \mathrm{mE} / 2052405 \mathrm{mN}$, collapsed in their upper stories (figure 6). The remodeled domed roof constructed with modern concrete was destroyed. Nobody could say this super structure, where the President meets with his ministers, was built without engineering criteria.

Project engineers would probably have responded that the building structure was safe before the earthquake hit the area. This again promotes the necessity of incorporating seismic response criteria into any engineering assessment. Figures 7, 8 and 9 show another shear-wave assessment for a site with low shear wave velocity in the vicinity of the Haitian national palace.

Similarly, the Cathedral of Port-au-Prince suffered the total collapse of its roof (figure 10), causing the death of several Haitian church leaders.

The majestic Montana hotel, built to the North of Pétionville, and next to the point defined by the coordinates $0785280 \mathrm{mE} / 2050620 \mathrm{mN}$, is a special case. The high eastern part, built on marly clay, collapsed completely. In contrast, the central part, housing the conference room, was raised on limestone bedrock, and 
suffered no damage. Moreover, the west side, opened on December 21, 2009 and built on marl, collapsed almost completely, although the damage was not comparable to that seen on the east side. Structural engineers must analyze the diverse effects seen at this site (figure 11) and incorporate these experiences in future designs.

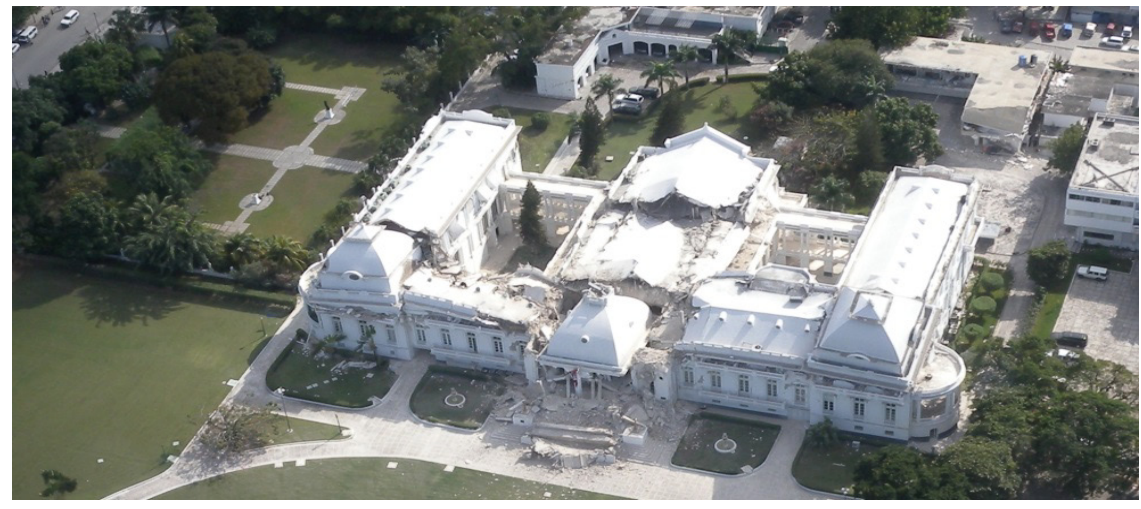

Figure 6: Haitian Government's palace, raised on the clay soils of the city.

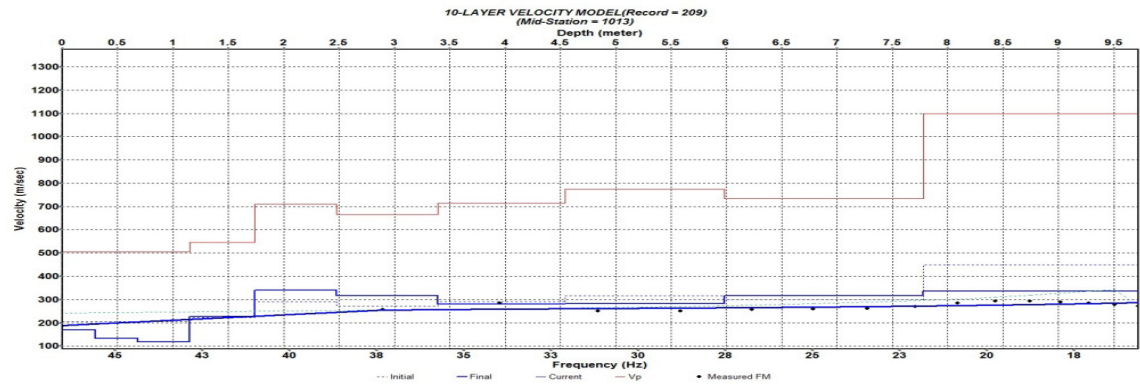

Figure 7: Representative1D shear-wave velocity profile from the north area of the Haitian national palace.

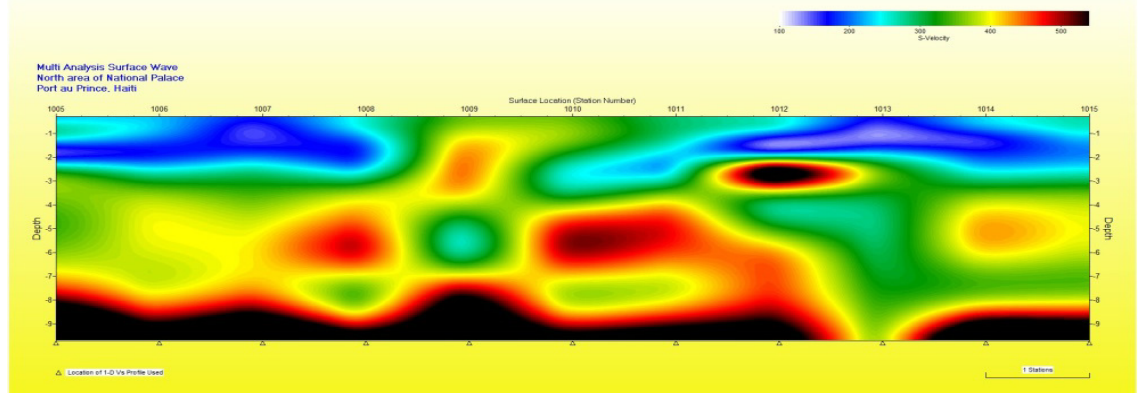

Figure 8: $\quad$ Pseudo 2D shear-wave velocity profile from the north area of the Haitian National Palace. 


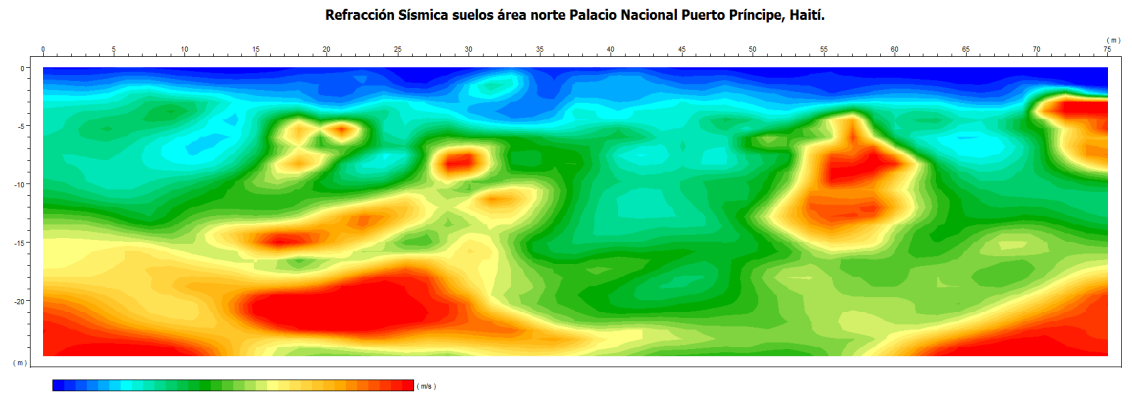

Figure 9: P-wave tomography of the north area of the Haitian National Palace.

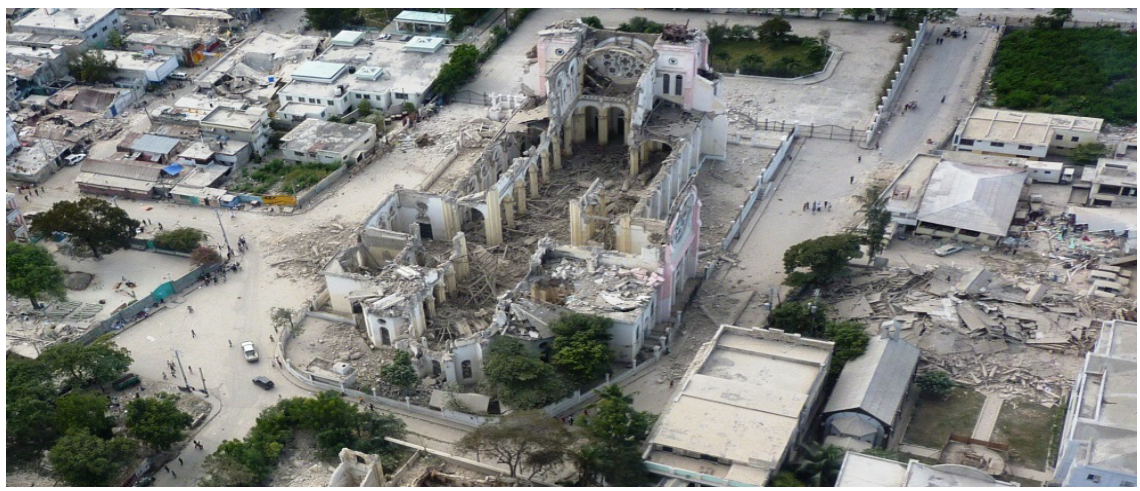

Figure 10: Cathedral of Port-au-Prince, built on clay soils. Note the destruction of the roof.

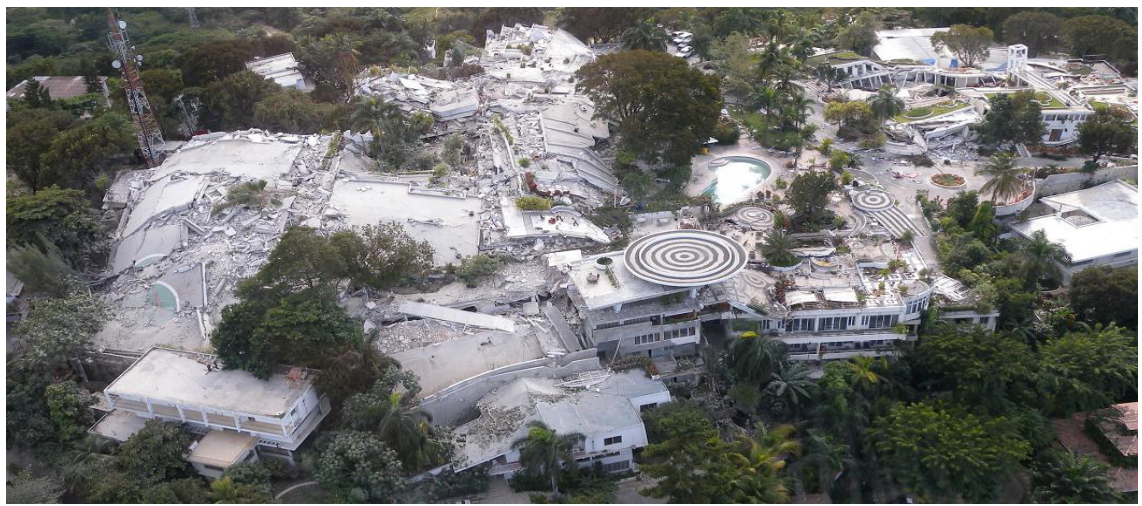

Figure 11: Famous Montana Hotel, over marl and clay, destroyed. 


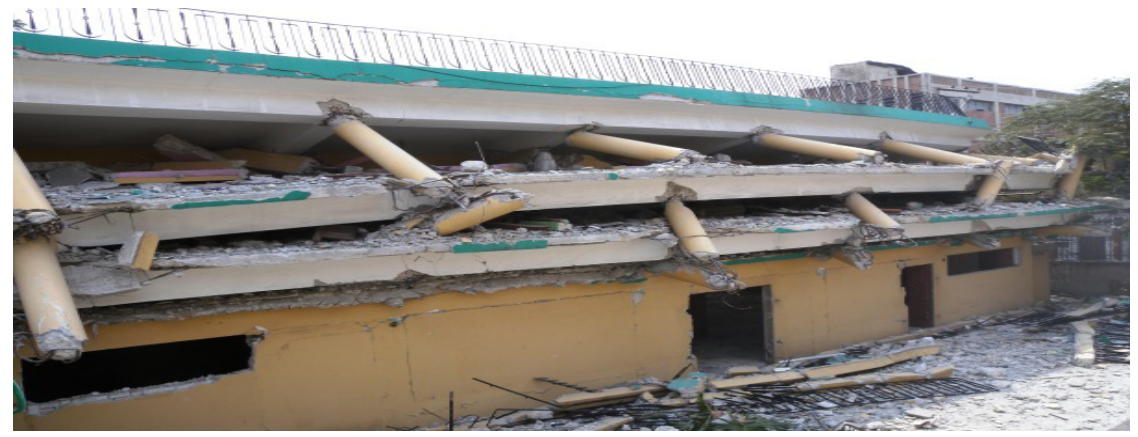

Figure 12: Salesian school of Haiti, located on clay soil.

The Salesian school of Port-au-Prince was built across four blocks, on the clay soils of the west area of the city, next to the point defined by the coordinates $0781200 \mathrm{mE} / 2052750 \mathrm{mN}$. The first level was supported by load-bearing walls and the three higher levels were supported by circular columns. Looking at figure 12 , we can see that the load-bearing walls remained intact, while the columns were completely compromised.

Evidently the load bearing walls were able to absorb the shear stress, while the isolated columns were not able to withstand the strong shear forces generated by the earthquake (De León [7]).

We find that most construction projects do not perform soil dynamic studies. Furthermore, the ministry of public works only requires a few mechanical boreholes that include standard penetration tests (SPT) and testing laboratories (grain size and Atterberg limits) to determine the bearing capacity of soils and settlement. This level of analysis does not meet the necessary standard to safely build in areas where earthquake hazards exist.

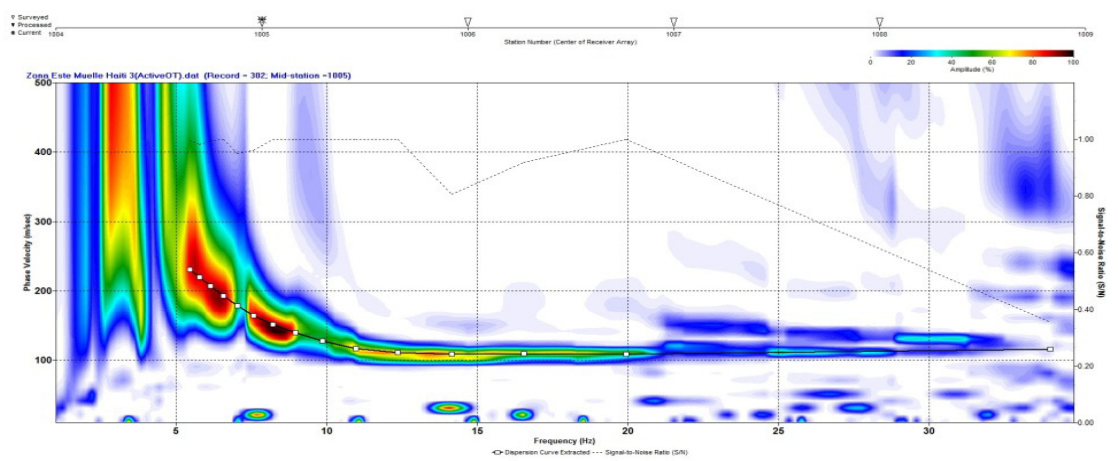

Figure 13: Phase velocity versus frequency. East side of the Port-au-Prince harbor, Haiti. 


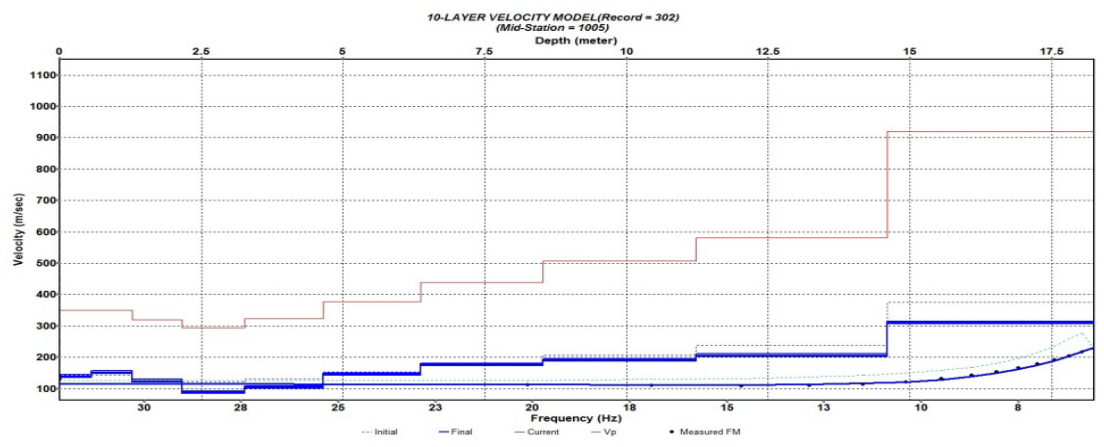

Figure 14: $\quad \mathrm{P}$ and shear waves with very soft soils between 1.3 and $4.5 \mathrm{~m}$ deep. Haiti.

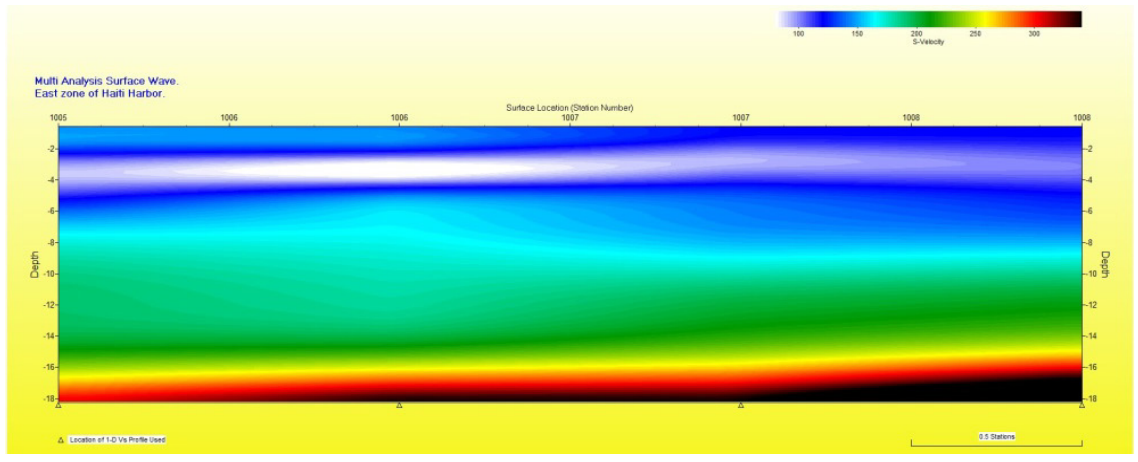

Figure 15: Shear waves showing very soft soils between 1.3 and $4.5 \mathrm{~m}$ deep.

Although these types of tests are important, they cannot replace the dynamic tests carried out with seismic investigation, and in particular those approaches that investigate the propagation of shear-wave velocities of the near surface. These are emphasized as much of the energy of an earthquake is traveling as surface waves, which often cause the majority of structural damage. The particle motion of those wave modes may result in the collapse of isolated columns and poorly constructed structures in response to amplified shear-component stress in the presence of low shear-strength materials (which are correlated to low shearvelocity material/soils).

Both Haiti and the Dominican Republic must immediately revise building codes to incorporate earthquake resistance criteria, giving priority to the seismic microzonation of all population centers. These zones would be based on seismic propagation velocities of shear waves, which would correlate to different levels of structural integrity and seismic-resistant building codes. Taking into consideration the experience of the Haiti earthquake, we have seen many buildings erected on soft and flexible soils to be sensitive to strong ground motion, and an opposite response for the buildings erected on the hard limestone outcrops on the road from Pétionville to Fermate (figure 16). 


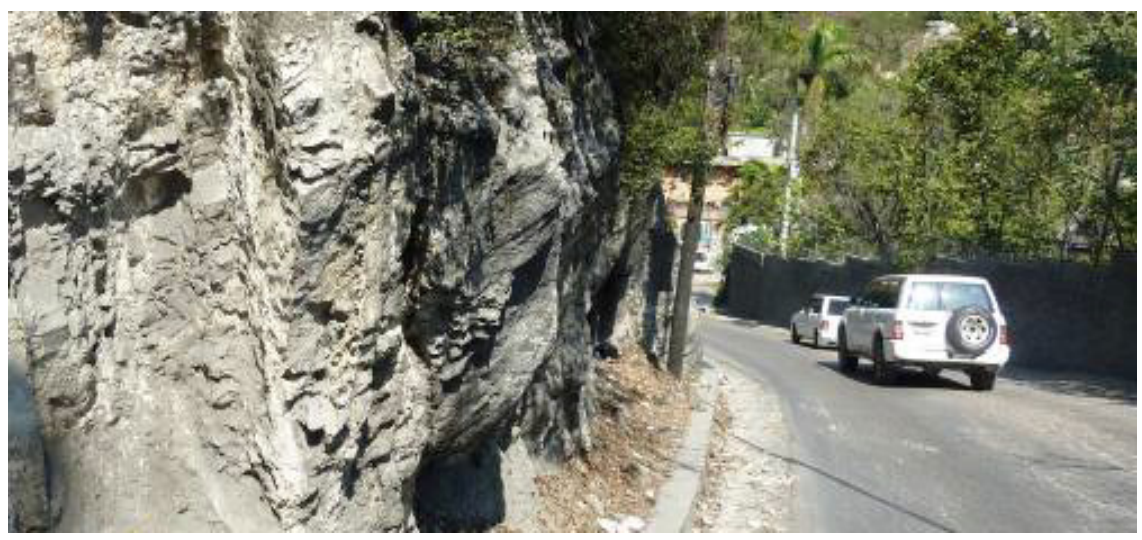

Figure 16: Very hard limestone rock of south hills of Port au Prince.

\section{Discussions}

The 2010 earthquake of Port-au-Prince, located on the southwestern area of the Hispaniola Island, was the most devastating earthquake in the island's history. This disaster was particularly extensive as the epicenter was close to a dense and poor urban area raised over low-shear strength soils. The low propagation velocities of shear waves, and a focal point, or hypocenter, just 10 kilometers deep, concentrated most of the energy(equivalent to 32 million tons of dynamite), in a relatively small area where foundation material lead to increased amplification and the devastation of major sections of the city.

Propagation velocities of shear seismic waves (Vs) on the east side of the Port au Prince harbor, shows that a horizon from $1.3 \mathrm{~m}$ to 4.5 meters deep has a shear-wave velocity (Vs) of approximately 75 meters per second. We may infer that this material has low shear-strength, and therefore, would cause amplification of strong ground motion.

In the southern mountainous area of Pétionville, where limestone bedrock is present at the surface, the buildings did not suffer any type of damage, not even cracks, in the poorly built structures erected without any engineering forethought, as we can see in figure 17. Conversely, we see another site, built on limestone, that saw little damage.

Figure 18 shows a building, with more than soft two floors, constructed over limestone bedrock, in the south area of Pétionville, with no damage after the Haiti earthquake.

Figure 19 shows the UNI bank building, placed over the soft clay of Port au Prince Plain. The first floor was destroyed during the Haiti earthquake. 


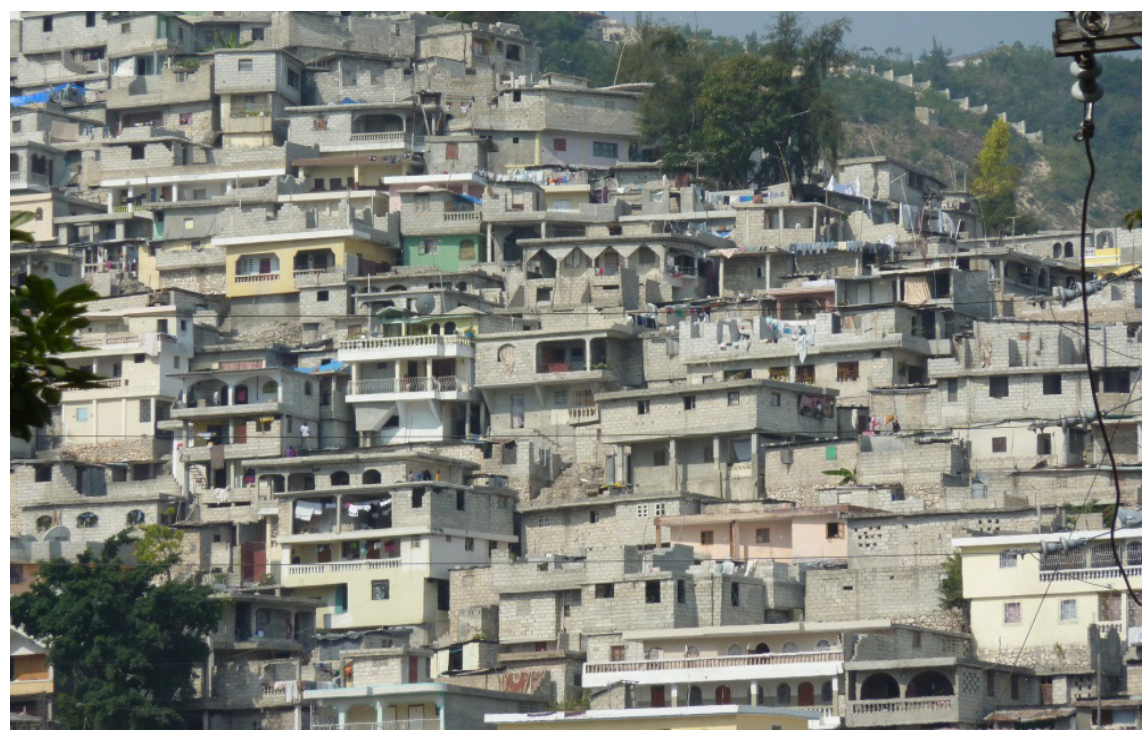

Figure 17: Picture of a dense village compound, in the hard limestone rock of south hills of city. Note the lack of damage.

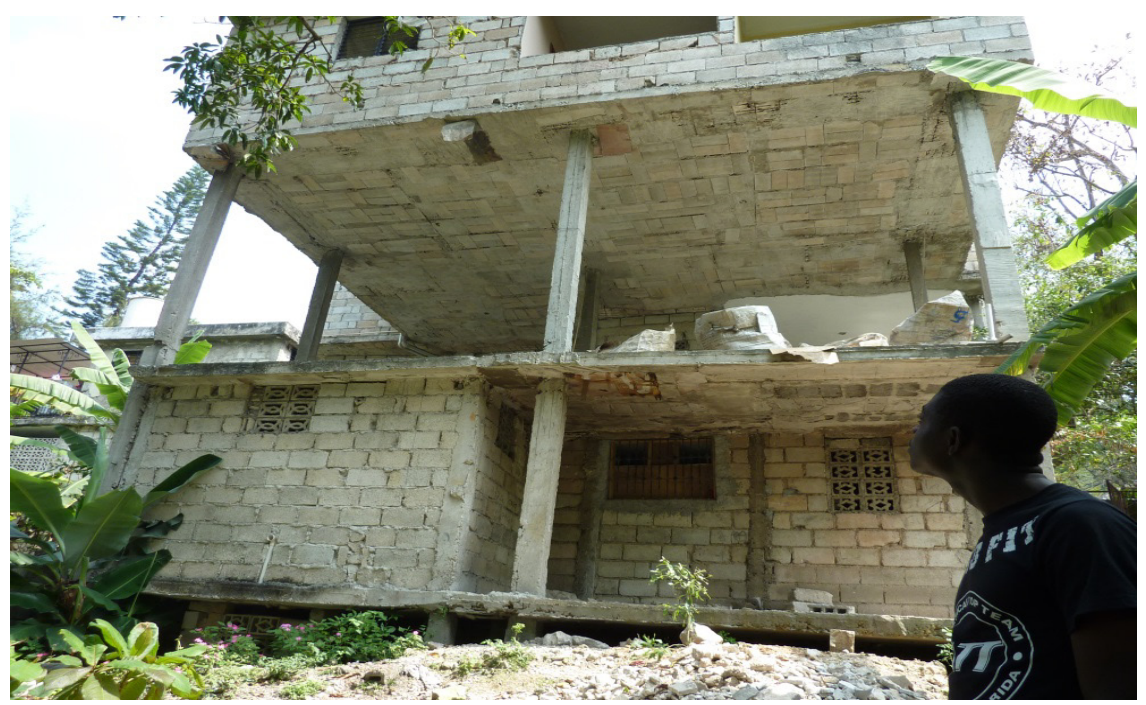

Figure 18: House with second soft level, built on the limestone bedrock. 


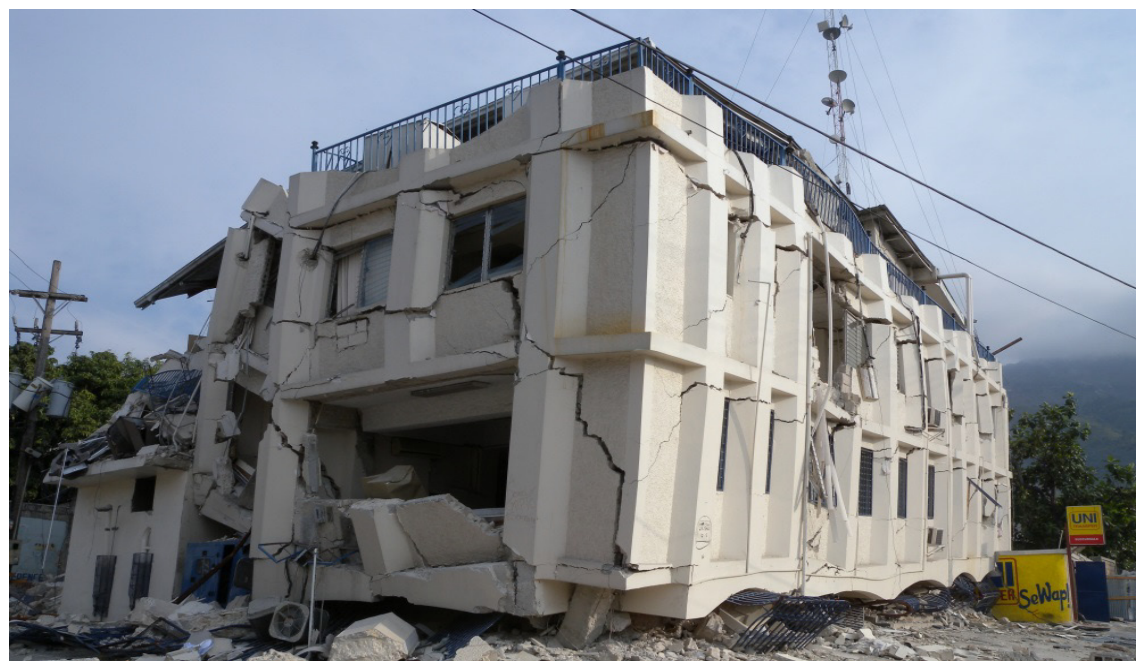

Figure 19: UNI bank building, over soft clay, with first level collapsed.

\section{Conclusions}

It is clear that after the seismic disaster of Haiti, dated $12^{\text {th }}$ January 2010 , when a 7.0 magnitude earthquake caused the death of 316,000 people, in civil engineering, there is much to learn and apply from the effects of earthquakes in the presence of various local near-surface material properties. These material characteristics should relate to building criteria designed to combat amplification, etc. For example, isolated columns in use on top of soft and flexible soils, must be increased in diameter to handle greater shear deformation. This applies to all buildings, but particularly to the construction of schools, hospitals, towers, malls, and service and strategic institutions.

Future engineering seismic design must be in accordance with shear-wave velocity measurements made at building site to avoid or reduce disasters, as seen in Haiti.

\section{Acknowledgement}

Many thanks to Jacob Tyler Schwenk of Kansas Geological Survey for his cooperation.

\section{References}

[1] De León, R.O., The Haiti earthquake. Verdor Magazine, Earthquake special edition from Sciences Academy of Dominican Republic. 6 (10), pp. 22-27, 2012. 
[2] De León, R.O., Influence of soft soils in the extensive damages of Haiti earthquake. Verdor Magazine, Earthquake special edition from Sciences Academy of Dominican Republic. 6 (10), pp. 28-39, 2012.

[3] Park, C.B., R.D. Miller, and J. Xia, 1999, Multichannel analysis of surface waves: Geophysics, v. 64, p. 800-808.

[4] J. Xia, R.D. Miller, and Park, C.B., 1999, Estimation of near-surface velocity by inversion of Raleigh waves: Geophysics, v. 64, p. 691-700.

[5] De León, R.O., The Haiti and Chile earthquakes. Verdor Magazine, Earthquake special edition from Sciences Academy of Dominican Republic. 6 (10), pp. 40-44, 2012.

[6] De León, R.O., Earthquakes, rocks and soils. Verdor Magazine, Earthquake special edition from Sciences Academy of Dominican Republic. 6 (10), pp. 54-71, 2012.

[7] De León, R.O., Buildings with soft floors. Verdor Magazine, Earthquake special edition from Sciences Academy of Dominican Republic. 6 (10), pp. 88-97, 2012. 